\title{
2 Why Have Meetings?
}

\section{After working through this section you will be able to list the different functions meetings perform.}

Meetings can fulfil any one or a combination of the following functions:

1 to consult with those concerned with the subject of the meeting, to sound their opinions, hold discussion and exchange views

2 to arrive at a decision

3 to pool expertise and ideas, to solve problems or arrive at recommendations

4 to implement decisions (executive committee) or to put forward recommendations (advisory committee)

5 to plan work or to monitor and discuss work progress

6 to inform employees about new work or procedures or other matters

7 to carry out negotiations

8 to investigate or to judge issues

As you can see from this list, meetings do perform very important functions. We can't really do without them if effective communication and decision-making, adequate preparation, planning and monitoring and good consultation are to take place, and all these are essential if any organisation is to function successfully.

Of course, not all meetings fulfil all of these functions. Each type of meeting - and there are many different types - will have its own specific purpose and function.

Broadly speaking, there are two major categories of meeting: formal and informal. Within these two categories are many different types, with specific objectives and tasks. These are largely evident from their titles. 